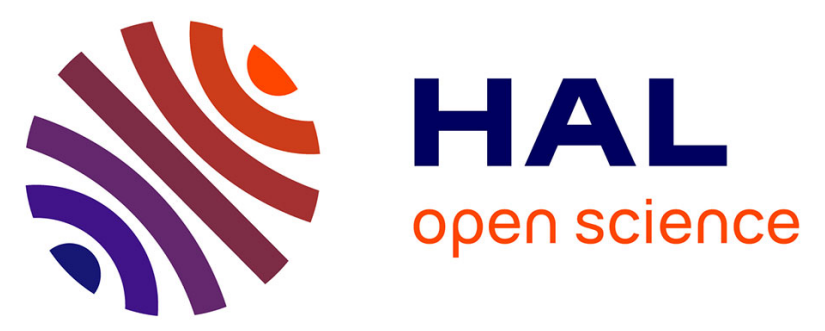

\title{
Apelin and APJ regulation in adipose tissue and skeletal muscle of type 2 diabetic mice and humans.
}

\author{
Cédric Dray, Cyrille Debard, Jennifer Jager, Emmanuel Disse, Danièle \\ Daviaud, Pascal G.P. Martin, Camille Attané, Estelle Wanecq, Charlotte \\ Guigné, Frédéric Bost, et al.
}

\section{To cite this version:}

Cédric Dray, Cyrille Debard, Jennifer Jager, Emmanuel Disse, Danièle Daviaud, et al.. Apelin and APJ regulation in adipose tissue and skeletal muscle of type 2 diabetic mice and humans.. AJP Endocrinology and Metabolism, 2010, 298 (6), pp.E1161-9. 10.1152/ajpendo.00598.2009 . inserm00506117

\section{HAL Id: inserm-00506117 https://www.hal.inserm.fr/inserm-00506117}

Submitted on 31 May 2020

HAL is a multi-disciplinary open access archive for the deposit and dissemination of scientific research documents, whether they are published or not. The documents may come from teaching and research institutions in France or abroad, or from public or private research centers.
L'archive ouverte pluridisciplinaire HAL, est destinée au dépôt et à la diffusion de documents scientifiques de niveau recherche, publiés ou non, émanant des établissements d'enseignement et de recherche français ou étrangers, des laboratoires publics ou privés. 


\title{
Apelin and APJ regulation in adipose tissue and skeletal muscle of type 2 diabetic mice and humans
}

\author{
Cédric Dray, ${ }^{1,2}$ Cyrille Debard, ${ }^{3}$ Jennifer Jager, ${ }^{4}$ Emmanuel Disse, ${ }^{5}$ Danièle Daviaud, ${ }^{1,2}$ Pascal Martin, ${ }^{6}$ \\ Camille Attané, ${ }^{1,2}$ Estelle Wanecq, ${ }^{1,2}$ Charlotte Guigné,,${ }^{1,2}$ Frédéric Bost, ${ }^{4}$ Jean-François Tanti, ${ }^{4}$ \\ Martine Laville, ${ }^{5}$ Hubert Vidal, ${ }^{3}$ Philippe Valet, ${ }^{1,2}$ and Isabelle Castan-Laurell ${ }^{1,2}$ \\ ${ }^{1}$ Institut National de la Santé et de la Recherche Médicale (INSERM), Unité 858, Toulouse; ${ }^{2}$ Université de Toulouse, \\ Université Paul Sabatier, Institut de Médecine Moléculaire de Rangueil, Toulouse, cedex 4; ${ }^{3}$ INSERM Unité 870, Institut \\ National de Recherche Agronomique (INRA) Unité 1235, Institut National des Sciences Appliquées (INSA) de Lyon, \\ Université Lyon 1, Faculté de médecine Lyon-Sud, Oullins; ${ }^{4}$ INSERM Unité 895, Centre de Médecine Moléculaire, Université \\ de Nice Sophia-Antipolis, Nice; ${ }^{5}$ Centre de Recherche en Nutrition Humaine Rhône-Alpes, Hospices Civils de Lyon, INSERM \\ Unité 870, INRA Unité 1235, INSA de Lyon, Université Lyon 1, Hôpital Lyon-Sud, Pierre-Bénite; and ${ }^{6}$ Laboratoire de \\ Pharmacologie et Toxicologie, Institut National de la Recherche Agronomique, INRA UR66, Toulouse, France
}

Submitted 28 September 2009; accepted in final form 10 March 2010

Dray C, Debard C, Jager J, Disse E, Daviaud D, Martin P, Attané C, Wanecq E, Guigné C, Bost F, Tanti J, Laville M, Vidal H, Valet P, Castan-Laurell I. Apelin and APJ regulation in adipose tissue and skeletal muscle of type 2 diabetic mice and humans. Am J Physiol Endocrinol Metab 298: E1161-E1169, 2010. First published March 16, 2010; doi:10.1152/ajpendo.00598.2009.-Apelin, an adipocyte-secreted factor upregulated by insulin, is increased in adipose tissue (AT) and plasma with obesity. Apelin was recently identified as a new player in the control of glucose homeostasis. However, the regulation of apelin and APJ (apelin receptor) expression in skeletal muscle in relation to insulin resistance or type 2 diabetes is not known. Thus we studied apelin and APJ expression in AT and muscle in different mice models of obesity and in type 2 diabetic patients. In insulin-resistant high-fat (HF)-fed mice, apelin and APJ expression were increased in AT compared with control. This was not the case in AT of highly insulinresistant $d b / d b$ mice. In skeletal muscle, apelin expression was similar in control and HF-fed mice and decreased in $d b / d b$ mice. APJ expression was decreased in both HF-fed and $d b / d b$ mice. Control subjects and type 2 diabetic patients were subjected to a hyperinsulinemic-euglycemic clamp, and tissues biopsies were obtained before and at the end of the clamp. There was no significant difference in basal apelin and APJ expression in AT and muscle between control and diabetic patients. However, apelin plasma levels were significantly increased in diabetic patients. During the clamp, hyperinsulinemia increased apelin and APJ expression in AT of control but not in diabetic subjects. In muscle, only APJ mRNA levels were increased in control but also in diabetic patients. Taken together, these data show that apelin and APJ expression in mice and humans is regulated in a tissue-dependent manner and according to the severity of insulin resistance.

insulin resistance; adipokine; insulin

APELIN IS A CIRCULATING PEPTIDE expressed in different tissues but also produced and secreted by human and mouse adipocytes (2). Apelin production in adipose tissue (AT) is strongly upregulated by insulin, and plasma concentrations are increased in obese and hyperinsulinemic mice and humans (2, 11). However, there are controversies in the literature regarding the regulation of apelin in subjects with altered glucose metabolism. In patients with newly diagnosed and untreated

Address for reprint requests and other correspondence: I. Castan-Laurell, I2MR, IFR 150, BP 84225, 31432 Toulouse cedex 4, France (e-mail: isabelle. castan@inserm.fr). type 2 diabetes, plasma apelin levels were decreased $(10,18)$. Increased plasma levels of apelin were observed in lean individuals with glucose intolerance and type 2 diabetes (17) and recently in morbidly obese patients with type 2 diabetes (21). These studies underline a link between apelin and type 2 diabetes. Recently, we demonstrated that intravenous apelin injection promotes glucose utilization in AT and skeletal muscles of control and obese, insulin-resistant mice (8). These data support a physiological role of this peptide in glucose homeostasis regulation. In addition, Yue et al. (23) showed that apelin-deficient $\left(\mathrm{Ape}^{-1-}\right)$ mice, especially on a high-fat diet (HFD), have decreased insulin sensitivity.

Apelin acts through the binding to a specific $G$ proteincoupled receptor named APJ (22). Apelin and APJ mRNA are widely expressed in mammalian tissues and are associated with functional effects in both the central nervous system and peripheral tissues (3). Apelin and APJ receptor are often colocalized in the same tissues and display similar variations of expression. For example, coordinated downregulation (13) or increased expression (1) of apelin and APJ has been observed in human or rodent heart with cardiac dysfunction. In obese subjects, we recently showed that the expression of both apelin and APJ was increased in AT (4).

So far, the regulation of APJ expression in skeletal muscle has not yet been studied. Moreover, the impact of insulin resistance and type 2 diabetes on the expression of these new actors of glucose metabolism remains to be addressed. Therefore, in the present study, we investigated the AT and skeletal muscle expression of apelin and APJ as well as plasma apelin levels in mouse models displaying different stages of insulin resistance and in type 2 diabetic patients. Furthermore, we studied apelin and APJ regulation during hyperinsulinemiceuglycemic clamp in humans and during the fasting-refeeding transition in mouse models. The data presented herein show that apelin and APJ expression are differently regulated according to the tissue and the severity of insulin resistance.

\section{MATERIALS AND METHODS}

Animal Studies

Housing and diets. Animals were handled in accordance with the principles and guidelines established by the National Institute of Medical Research (INSERM). All protocols were approved by the 
local ethics committee. C57B16/J wild-type and $d b / d b$ mice were obtained from Charles River Laboratory (l'Arbresle, France). Mice were housed conventionally in a constant temperature $\left(20-22^{\circ} \mathrm{C}\right)$ and humidity (50-60\%) animal room, with a 12:12-h light-dark cycle (lights on at 8:00 A.M.) and free access to food and water. The C57B16/J mice were fed a chow diet from weaning until 10 wk old and then either maintained on a normal chow diet (control group) or fed a HFD containing $20 \%$ protein, $35 \%$ carbohydrate, and $45 \%$ fat (Research Diet). HF-fed mice were followed at regular intervals with a measure of body weight and blood parameters (glucose and insulin) until they were obese and insulin resistant. Thus HF-fed mice, agematched control, and $d b / d b$ mice (fed a chow diet) were killed between 32 and $38 \mathrm{wk}$ old. Youger $d b / d b$ mice from 10 to $16 \mathrm{wk}$ old were also used as a model of a less-advanced stage of insulin resistance.

Intraperitoneal glucose tolerance test. An intraperitoneal injection of glucose ( $1 \mathrm{~g} / \mathrm{kg}$ of body wt) was performed in 12-h-fasted mice. Blood was collected from the tip of the tail vein, and glucose levels were monitored with a glucometer (Roche Diagnostic, Rotkreuze, Switzerland) at 0, 20, 40, 60, 90, and 120 min after glucose injection.

Intraperitoneal insulin tolerance test. An intraperitoneal injection of human insulin $(0.75 \mathrm{U} / \mathrm{kg}$ of body wt) was performed in 12-h-fasted mice. Blood was collected from the tip of the tail vein, and glucose levels were monitored with a glucometer (Roche Diagnostic) at 0, 20, 40, 60, 90, and $120 \mathrm{~min}$ after insulin injection.

Nutritional regulation and tissue sampling. Mice were fed or fasted for $24 \mathrm{~h}$ or refed during $24 \mathrm{~h}$ after $24 \mathrm{~h}$ fasting. At the time of death, blood was collected through the inferior cava vein on $0.1 \%$ EDTA for glucose levels (glucometer; Roche Diagnostic) as well as for plasma insulin and apelin determination (see below). Tissues were taken and either immediately frozen for mRNA determination or used for glucose transport in adipocytes or skeletal muscle.

Plasma parameters. Plasma insulin and apelin concentrations were measured using an ultrasensitive mouse insulin ELISA (Mercodia, Uppsala, Sweden) and a nonselective apelin-12 EIA kit (Phoenix Pharmaceuticals, Belmont, CA), respectively. Leptin was measured with a Milliplex MAP kit for mouse serum adipokine (Millipore, St. Charles, MO).

\section{Human Study}

Subjects. All participants gave their written consent after being informed of the nature, purpose, and possible risks of the study. The experimental protocol was approved by the Ethical Committees of the Hospices Civils de Lyon and performed according to the French legislation (Huriet Law). Fourteen patients with type 2 diabetes (mean $\mathrm{HbA}_{1 \mathrm{c}}=8.9 \pm 0.5 \%$ ) participated in the study. All were treated only with oral antidiabetic agents (metformin and/or sulfonylurea). They interrupted, under medical control, their usual treatment at least 5 days before the investigation. They were compared with 14 healthy lean control subjects. None of them had impaired glucose tolerance or a familial or personal history of diabetes, obesity, dyslipidemia, or hypertension. The characteristics of the subjects are presented in Table 1.

Hyperinsulinemic clamp. All studies were performed after an overnight fast. To investigate insulin action on glucose metabolism and on gene expression in peripheral tissues, the subjects were submitted to a 3-h euglycemic-hyperinsulinemic clamp (insulin infusion rate of $\left.2 \mathrm{mU} \cdot \mathrm{min}^{-1} \cdot \mathrm{kg}^{-1}\right)$, as previously described $(9,16)$. Plasma metabolite and hormones concentrations were measured using enzymatic methods and radioimmunoassays.

\section{In Vitro Studies}

Human preadipocyte culture. Human preadipocytes (Biopredic, Rennes, France) were grown at $5 \% \mathrm{CO}_{2}$ and $37^{\circ} \mathrm{C}$ in 12 -well collagen-coated plates in DMEM Ham's F-12 containing 15 mM HEPES, $2 \mathrm{mM}$ L-glutamine, $5 \%$ FCS, $1 \%$ antimycotic solution, endothelial cell
Table 1. Metabolic characteristics of the subjects

\begin{tabular}{lcc}
\hline \hline & & Type 2 Diabetic \\
& Control Subjects & Patients \\
\hline$n$ & 14 & 14 \\
Sex $(\mathrm{M} / \mathrm{F})$ & $5 / 9$ & $9 / 5$ \\
Age, $\mathrm{yr}$ & $41 \pm 3$ & $54 \pm 2$ \\
BMI, $\mathrm{kg} / \mathrm{m}^{2}$ & $23.0 \pm 0.4$ & $31.0 \pm 1.3^{*}$ \\
Fasting glucose, $\mathrm{mmol} / \mathrm{l}$ & $4.9 \pm 0.1$ & $9.5 \pm 0.6^{*}$ \\
Fasting insulin, pmol/1 & $39 \pm 3$ & $72 \pm 10 \dagger$ \\
NEFA, $\mu \mathrm{M}$ & $515 \pm 58$ & $588 \pm 40$ \\
Triglycerides, $\mu \mathrm{M}$ & $790 \pm 91$ & $1,501 \pm 209 \dagger$ \\
Clamp study & & \\
$\quad$ Glucose, $\mathrm{mmol} / \mathrm{l}$ & $4.8 \pm 0.1$ & $5.0 \pm 0.2$ \\
$\quad$ Insulin, $\mathrm{pmol} / \mathrm{l}$ & $1,038 \pm 49$ & $1,032 \pm 54$ \\
$\quad$ Glucose disposal rate, $\mathrm{mg} \cdot \mathrm{kg}^{-1} \cdot \mathrm{min}^{-1}$ & $10.9 \pm 0.6$ & $5.0 \pm 0.6^{*}$ \\
$\quad$ & $37 \pm 3$ & $75 \pm 9 \dagger$ \\
\hline NEFA, $\mu \mathrm{M}$ &
\end{tabular}

Values are means $\pm \mathrm{SE} ; n$, no. of subjects/patients. $\mathrm{M}$, male; $\mathrm{F}$, female; BMI, body mass index; NEFA, nonesterified fatty acid. $* P<0.001$ and $\uparrow P<$ 0.05 , type 2 diabetic patients vs. control subjects.

growth supplement/heparin, human epidermal growth factor-5, and HC-500 from Supplement Pack Preadipocyte Growth Medium (Promocell). Differentiation in adipocytes was induced after confluence by changing the medium for DMEM Ham's F-12 to 15 mM HEPES, 2 $\mathrm{mM}$ L-glutamine, $3 \% \mathrm{FCS}$, supplemented with biotin $(33 \mu \mathrm{M})$, insulin $(100 \mathrm{nM})$, pantothenate $(17 \mu \mathrm{M})$, isobutyl methylxanthine $(0.2 \mathrm{mM})$, dexamethasone $(1 \mu \mathrm{M})$, and rosiglitazone $(10 \mu \mathrm{M})$. The medium was removed after 3 days and replaced with Ham's F-12 containing 15 mM HEPES, 2 mM L-glutamine, 10\% FCS, supplemented with biotin $(33 \mu \mathrm{M})$, insulin $(100 \mathrm{nM})$, pantothenate $(17 \mu \mathrm{M})$, and dexamethasone $(1 \mu \mathrm{M})$. Next, the cells were fed every 2 days with the same medium. Human adipocytes were used 9 days after the beginning of the differentiation protocol.

Glucose transport in mice adipocytes. A sample of perigonadic AT was minced, incubated while shaking in $5 \mathrm{ml}$ of Krebs-Ringer buffer supplemented with $1 \mathrm{mg} / \mathrm{ml}$ collagenase and $1 \%$ BSA, and digested for $30 \mathrm{~min}$ at $37^{\circ} \mathrm{C}$. After filtration, isolated adipocytes were incubated in the presence or absence of $100 \mathrm{nM}$ insulin for $45 \mathrm{~min}$ at $37^{\circ} \mathrm{C}$ in a final volume of $400 \mu \mathrm{l}$. Next, 2-deoxy-D- $\left[{ }^{3} \mathrm{H}\right]$ glucose $(2-\mathrm{DG})$ was added at a final concentration of $0.1 \mathrm{mM}$ for $10 \mathrm{~min}$. Assays were stopped with $100 \mu \mathrm{l}$ of $100 \mathrm{mM}$ cytochalasin B, and aliquots of the cell suspension were centrifuged in microtubes containing di-isononyl phthalate (density $0.974 \mathrm{~g} / \mathrm{ml}$ ) to separate adipocytes from the buffer and count the intracellular 2-DG.

Glucose transport in mice skeletal muscle. Soleus muscles were isolated and preincubated for $10 \mathrm{~min}$ in Krebs-Henseleit $(\mathrm{KH})$ buffer, $\mathrm{pH} 7.4$, containing $2 \mathrm{mg} / \mathrm{ml} \mathrm{BSA}, 2 \mathrm{mM}$ sodium pyruvate, and $20 \mathrm{mM}$ HEPES. Muscles were then incubated for $45 \mathrm{~min}$ in the presence or absence of insulin $(100 \mathrm{nM})$. For glucose transport, muscles were transferred in another vial containing $\mathrm{KH}$ medium supplemented with $0.1 \mathrm{mM} 2-\mathrm{DG}$ and $0.4 \mu \mathrm{Ci} / \mathrm{ml} 2-\mathrm{DG}$ for $10 \mathrm{~min}$. Muscles were then washed for $1 \mathrm{~h}$ in ice-cold iso-osmotic $\mathrm{NaCl}$ solution and dissolved in $1 \mathrm{M} \mathrm{NaOH}$ during $1 \mathrm{~h}$. D-Deoxy- $\left[{ }^{3} \mathrm{H}\right]$ glucose 6-phosphate and 2-DG were differentially precipitated by the use of zinc sulfate $(0.3 \mathrm{M})$, barium hydroxide $(0.3 \mathrm{M})$, and perchloric acid solutions $(6 \%)$. All of the incubations were carried out at $37^{\circ} \mathrm{C}$ under a $95 \% \quad \mathrm{O}_{2}-5 \% \mathrm{CO}_{2}$ atmosphere.

\section{Apelin and AJP mRNA Expression Studies}

Mice tissues. Tissues from fed mice (AT and muscle) were crushed by using a Precellys 24 automated biological sample lyser with CK-14 bead vials. Total RNAs $(1 \mu \mathrm{g})$ were isolated from AT using RNeasy Lipid Tissue Kits (QIAGEN) and from muscle using RNA STAT (AMS Technology). Total RNAs were reverse transcribed using random hexamers and Superscript II reverse transcriptase (Invitrogen). Real-time 

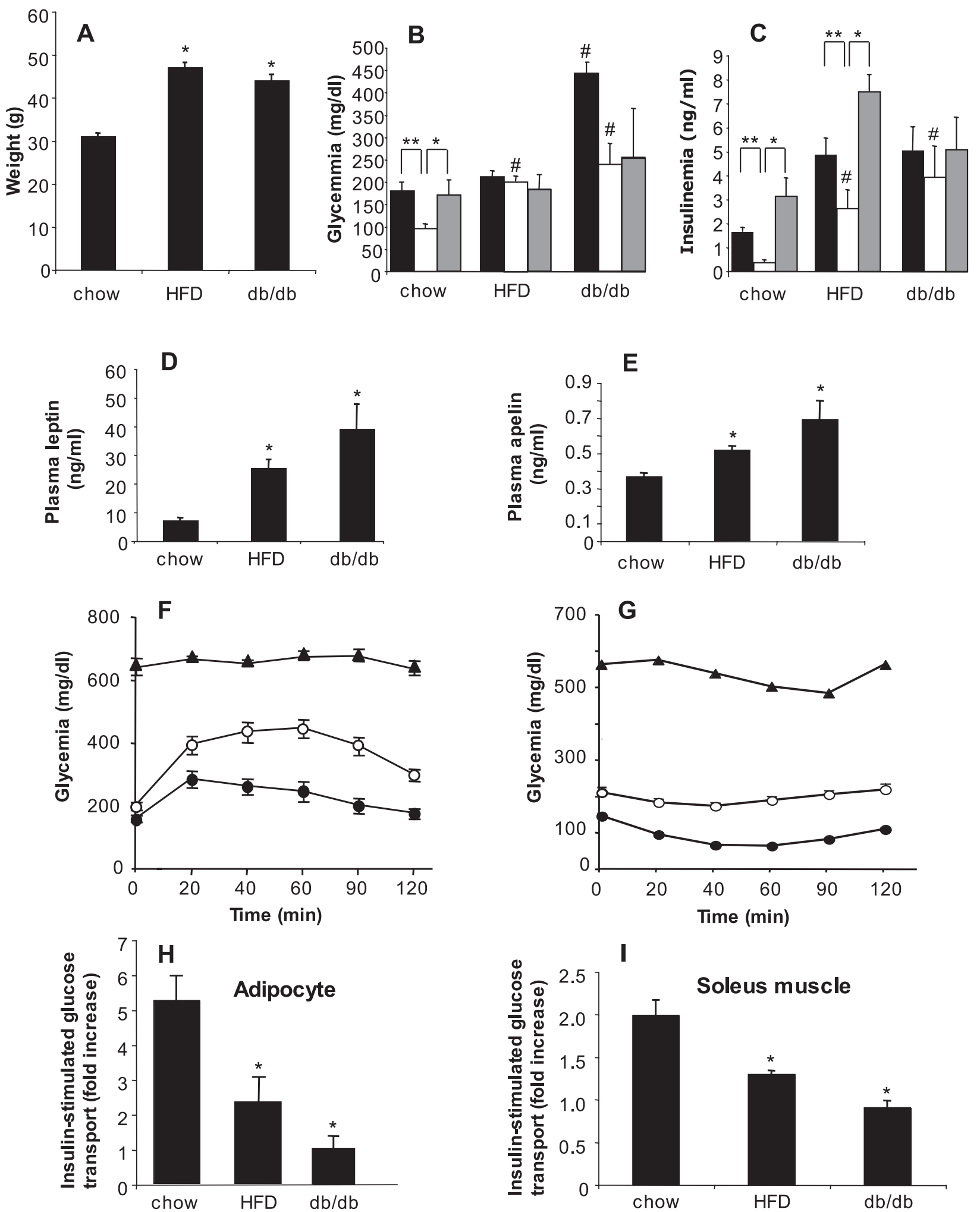

Fig. 1. Characteristics of high-fat (HF)-fed and $d b / d b$ mice compared with chow-fed mice. $A$ : body weight was measured in control (chow-fed), HF-fed, and $d b / d b$ mice at death (mice were from 32 to $38 \mathrm{wk}$ old). HFD, HF diet. Results are means \pm SE; $n=7-10$ mice/group. $* P<0.05 . B$ and $C$ : blood glucose levels $(B)$ and insulinemia $(C)$ measured in fed (black bars), fasted (white bars), and refed (gray bars) conditions at death as described in MATERIALS AND METHODS in chow-, HF-fed, and $d b / d b$ mice. Results are means \pm SE; $n=6-9$ mice for control and HFD mice and 4-7 for $d b / d b$ mice. ${ }^{*} P<0.05, * * P<0.01$, and $\# P<0.05$, HF-fed or $d b / d b$ vs. chow-fed mice. $D$ and $E$ : plasma leptin $(D)$ and apelin levels $(E)$, measured in the fed state, in chow-, HF-fed, and $d b / d b$ mice. Results are means \pm SE; $n=6-8$ mice/group. $* P<0.05$ vs. chow-fed mice. $F$ and $G$ : glucose tolerance test $(F)$ and insulin tolerance test $(G)$ were performed as described in MATERIALS AND METHODS in chow-fed $(n=9,0)$, HF-fed $(n=10, \bigcirc)$, and $d b / d b(n=4, \boldsymbol{\Delta})$ mice. Glucose was determined on blood samples from the tail vein with a glucometer at the indicated times. Values represent means \pm SE. $H$ and $I$ : glucose transport stimulated by insulin $(100 \mathrm{nM})$ in isolated adipocytes $(H)$ and in skeletal muscles $(I)$ of chow-, HF-fed, and $d b / d b$ mice. Results represent the ratio of insulin stimulated on basal transport (fold increase) and are means \pm SE; $n=5-7$ mice/group. *P<0 0.05 vs. chow-fed mice. 
PCR was performed as previously described (2). Briefly, real-time PCR was performed on $12.5 \mathrm{ng}$ cDNA with both sense and antisense oligonucleotides in a final volume of $20 \mu$ using SYBR Green qPCR Master Mix (Eurogentec, Seraing, Belgium). Fluorescence was monitored and analyzed in a GeneAmp 7500 detection system instrument (Applied Biosystems, Warrington, UK). In parallel, analysis of the 18S ribosomal RNA wad performed using the ribosomal RNA control Taqman Assay Kit (Applied Biosystems) to normalize gene expression.

Human tissues. Total RNA preparations from abdominal subcutaneous AT and skeletal muscle samples were performed as described previously $(7,9)$. The concentrations of apelin and APJ mRNAs were measured by RT followed by real-time PCR using a Light-Cycler (Roche Diagnostics, Meylan, France). First-strand cDNAs were first synthesized from $500 \mathrm{ng}$ of total RNA in the presence of 100 units of Superscript II (Invitrogen, Eragny, France) using both random hexamers and oligo(dT) primers (Promega, Charbonnières, France). The real-time PCR was performed in a final volume of $20 \mu$ l containing 5 $\mu l$ of a 60 -fold dilution of the RT reaction medium, $15 \mu \mathrm{l}$ of reaction buffer from the FastStart DNA Master SYBR Green kit (Roche Diagnostics), and 10.5 pmol of the specific forward and reverse primers. For quantification, a standard curve was systematically generated with six different amounts of cDNA. Each assay was performed in duplicate, and validation of the real-time PCR runs was assessed by evaluation of the melting temperature of the products and by the slope and error obtained with the standard curve. Hypoxanthine phosphoribosyltransferase mRNA level was determined in each sample and was used as internal standard for normalization of target mRNA expression.

\section{Statistical Analysis}

Data were analyzed under R 2.8.1 (www.r-project.org) and are presented as means \pm SE. Depending on the experimental design, log-transformed data were analyzed by one- or two-way ANOVA followed by a Student's $t$-test with a pooled variance estimate to compare the groups. Data from the hyperinsulinemic clamp study were analyzed by paired Student's $t$-test. Correlations were analyzed by Spearman's nonparametric test. A $P$ value $<5 \%$ was considered significant.

\section{RESULTS}

\section{Characteristics and Metabolic Parameters of the Different Mouse Models}

Compared with chow-fed mice at the same age, HF-fed mice were obese, hyperinsulinemic, and had higher levels of blood glucose (Fig. 1, $A-C$ ). Fasted glucose levels were significantly higher in HF-fed mice than in fasted control mice but did not differ from refeeding and fed states (Fig. 1B). In HF-fed mice, even though insulinemia was decreased during fasting, the level was significantly higher than in fasted control mice (Fig. $1 C$ ). The $d b / d b$ mice were also obese (Fig. 1A) and had higher blood glucose levels than HF-fed mice in the fed state (Fig. $1 B)$. They were also hyperinsulinemic and more hyperglycemic than HF-fed mice in the fasting state (Fig. 1C). Plasma leptin levels were increased in HF-fed mice and more dramatically in $d b / d b$ mice as expected (Fig. 1D). Plasma apelin levels were also increased in HF-fed mice as previously described (2, 8) as well as in $d b / d b$ mice (Fig. $1 E$ ). During the glucose tolerance test and the insulin tolerance test, HF-fed mice presented a profile of glucose intolerance and a loss of insulin sensitivity that was less pronounced than in $d b / d b$ mice (Fig. 1, $F$ and $G$ ). Moreover, HF-fed mice had significant impaired glucose transport measured in vitro in isolated adipocytes and soleus muscle (Fig. 1, $H$ and I). This decrease was more
Fig. 2. Expression of apelin and apelin receptor (APJ) in fed conditions in adipose tissue (AT; $A$ ) and skeletal muscle $(B)$ of chow-, HF-fed, and $d b / d b$ mice. Levels of mRNA were determined by RT-PCR as indicated in MATERIALS AND METHODS. NS, not significant. Results are means \pm SE; $n=6-8$ mice/ group. $* P<0.05$ and $* * P<0.01$.
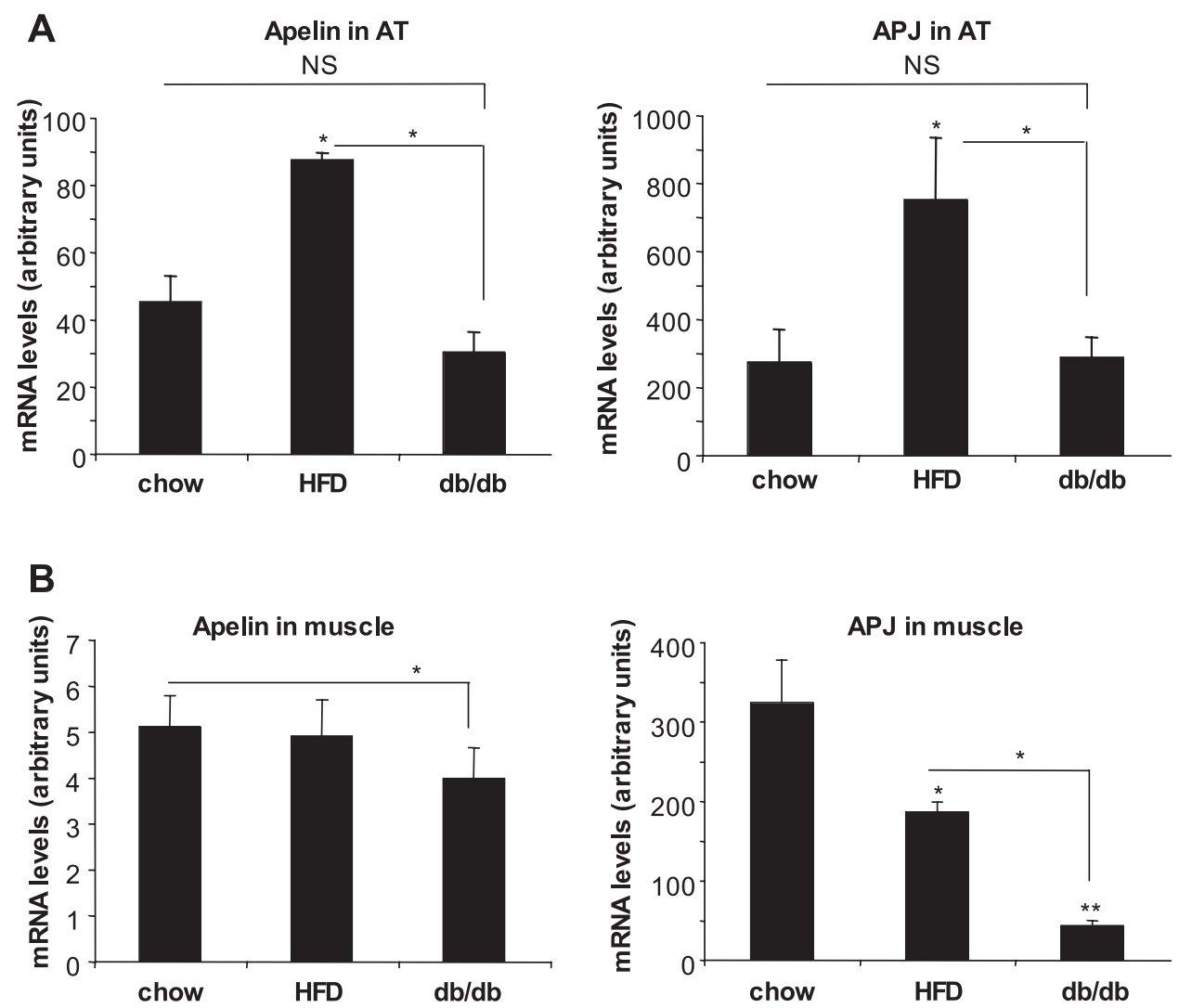
pronounced in $d b / d b$ mice. Thus HF-fed mice were clearly insulin resistant but less than $d b / d b$ mice.

\section{Mice Apelin and APJ Expression in AT and Muscle}

In fed conditions, apelin but also APJ expression was increased in AT of HF-fed insulin-resistant mice but not in AT of $d b / d b$ mice compared with chow-fed mice (Fig. $2 A$ ). In muscle, apelin expression was similar in control and HF-fed but decreased in $d b / d b$ mice. APJ expression was decreased in muscle of insulin-resistant mice compared with controls. This effect was more pronounced in $d b / d b$ mice (Fig. $2 B$ ). Experiments were also carried out in younger fed $d b / d b$ mice (from 10 to $16 \mathrm{wk}$ old) that have a less advanced insulin-resistant state (Fig. 3). Young $d b / d b$ mice were less hyperglycemic (399 \pm 25 $\mathrm{mg} / \mathrm{dl}, n=5)$ than old $d b / d b$ mice but more than HF-fed mice (see Fig. $1 B)$. They were as hyperinsulinemic $(4.7 \pm 0.6 \mathrm{pg} / \mathrm{ml}$, $n=5$ ) as old $d b / d b$ and HF-fed mice (see Fig. 1C). Even if statistical significance was not reached, the expression of apelin was higher in AT of young $d b / d b$ mice compared with old $d b / d b$ mice and similar to HF-fed mice (see Fig. 2). However, the expression of APJ in AT was not higher in young $d b / d b$ compared with old $d b / d b$ mice (Fig. 3). In skeletal muscle, mRNA levels of apelin and APJ were equivalent in young and old $d b / d b$ mice.

During the fasting/refeeding transition, apelin expression significantly increased in AT (2.8-fold) and in muscle (2.4fold) of control mice. These effects were less marked in the tissues of HF-fed mice (Fig. 4) and absent in AT and skeletal muscle of $d b / d b$ mice. APJ expression in AT tended to be increased upon refeeding in control mice $(P=0.084)$, and the effect was significant in HF-fed mice (Fig. 4). In skeletal muscle, APJ expression did not increase upon refeeding in control, HFD, and $d b / d b$ mice.

\section{Characteristics and Metabolic Parameters of the Subjects}

The lean control subjects and the moderately obese type 2 diabetic patients who participated in the study had classical metabolic characteristics (Table 1). In the basal state, after an overnight fast, plasma concentrations of glucose, insulin, and triglycerides were higher in type 2 diabetic patients than in control subjects. During the euglycemic-hyperinsulinemic clamp, insulinemia was maintained at similar supraphysiological concentration in both groups. Under such condition, the stimulation by insulin of whole body glucose utilization rate was profoundly reduced in type 2 diabetic patients, indicating a marked state of insulin resistance. In addition, nonesterified fatty acid concentrations during the clamp remained significantly higher in the type 2 diabetic patients (Table 1), also indicating a lower insulin response in AT.

\section{Insulin Regulation of Human Apelin and APJ Expression in AT and Muscle}

In the basal state, apelin and APJ mRNA levels were not significantly different between control subjects and type 2 diabetic patients, both in AT and in skeletal muscle, even though there were trends for an increased apelin expression in fat and for a decreased APJ expression in muscle of the type 2 diabetic patients (Fig. 5). To assess the effect of insulin in vivo, tissue biopsies were collected before and at the end of the 3-h hyperinsulinemic clamp. Hyperinsulinemia increased apelin and APJ expression in AT of control

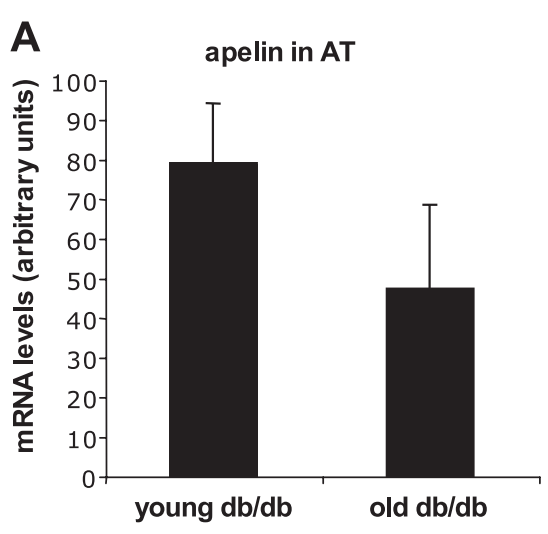

B

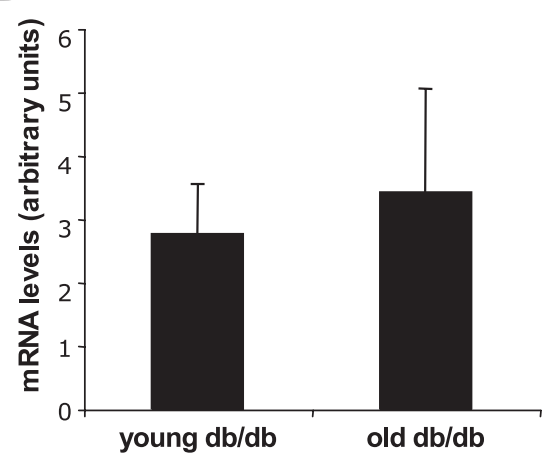

APJ in AT

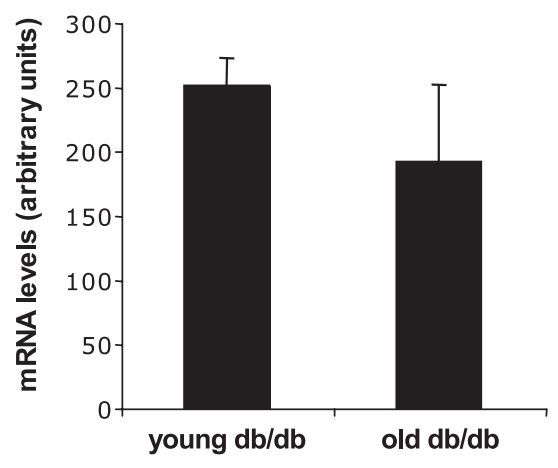

APJ in muscle

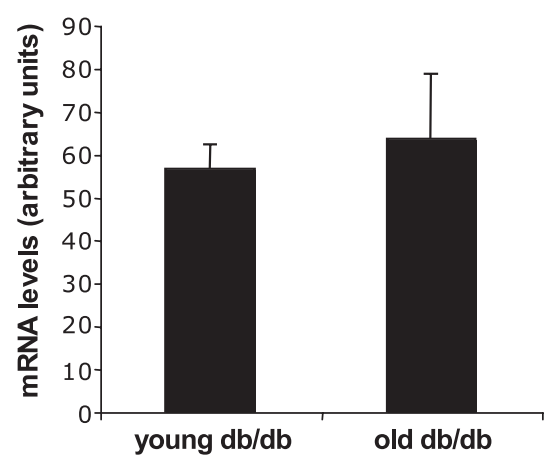

Fig. 3. Expression of apelin and APJ in fed conditions in AT $(A)$ and skeletal muscle $(B)$ of younger $d b / d b$ mice. Levels of mRNAs were determined by RT-PCR as indicated in MATERIALS AND METHODS. Old mice were from $38 \mathrm{wk}$ old, whereas young mice were from 10 to 16 wk old. Results are means $\pm \mathrm{SE} ; n=5$ mice/group. 
A

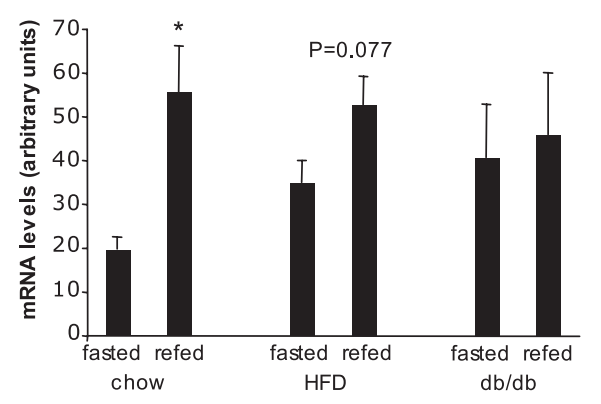

B

Fig. 4. Expression of apelin and APJ in AT $(A)$ and skeletal muscle $(B)$ during fasting/refeeding transition in chow-, HF-fed, and $d b / d b$ mice. Mice were either fasted during $24 \mathrm{~h}$ and killed (fasted) or fasted during $24 \mathrm{~h}$, refed during $24 \mathrm{~h}$, and then killed (refed). Levels of mRNAs were determined by RT-PCR as indicated in MATERIALS AND METHODS. Results are means $\pm \mathrm{SE} ; n=5-10$ mice for control and HFD mice and 4 for $d b / d b$ mice. ${ }^{*} P<0.05$, refed vs. fasted conditions.

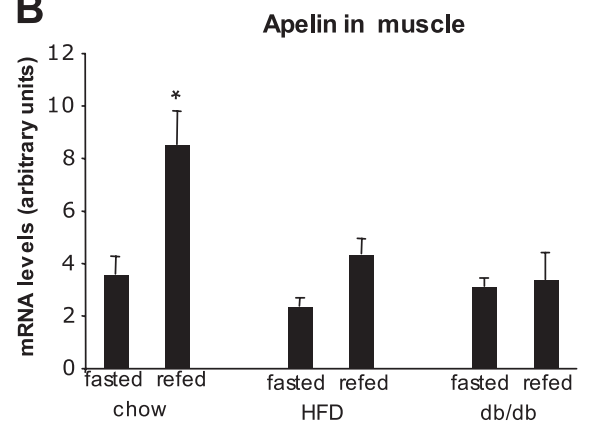

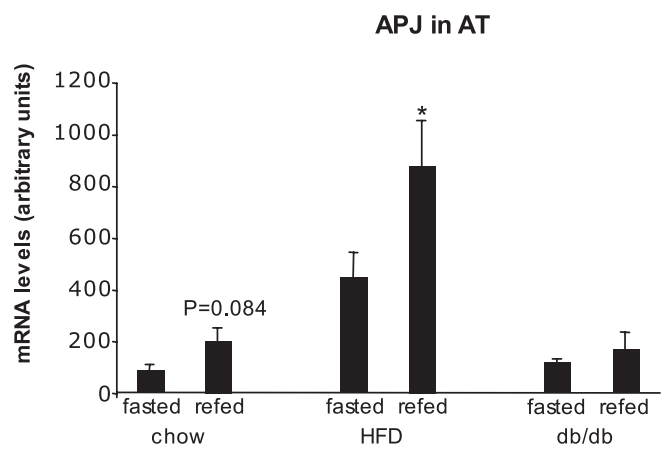

APJ in muscle

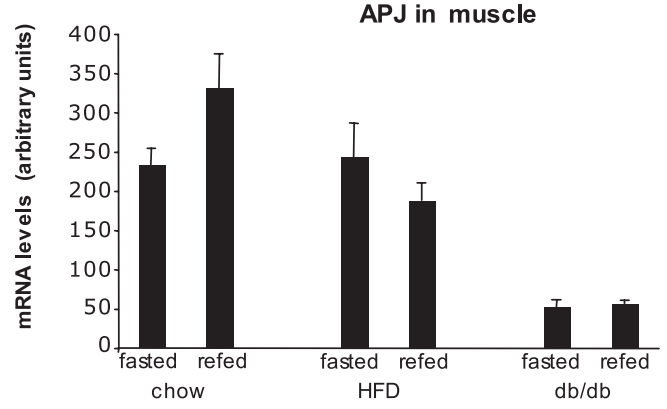

subjects (Fig. 5). This effect of insulin on apelin and APJ mRNAs was completely blunted in the AT of the type 2 diabetic patients. In skeletal muscle, apelin expression appeared to be not affected by $3 \mathrm{~h}$ of hyperinsulinemia, neither in control nor in diabetic subjects. In contrast, APJ mRNA levels were increased during the clamp. Although the effect was modest, the difference reached significance in the muscle of diabetic patients (Fig. 5).
Fig. 5. Expression of apelin and APJ in AT $(A)$ and skeletal muscle $(B)$ in control and diabetic patients before and after insulin infusion. Levels of mRNAs were determined by RT-PCR on AT and skeletal muscle biopsies taken before (open bars) and at the end (filled bars) of a 3-h hyperinsulinemic-euglycemic clamp as indicated in MATERIALS AND METHODS. Results are means \pm SE; $n=7$ mice/group. ${ }^{*} P<0.05$, after vs. before the clamp.
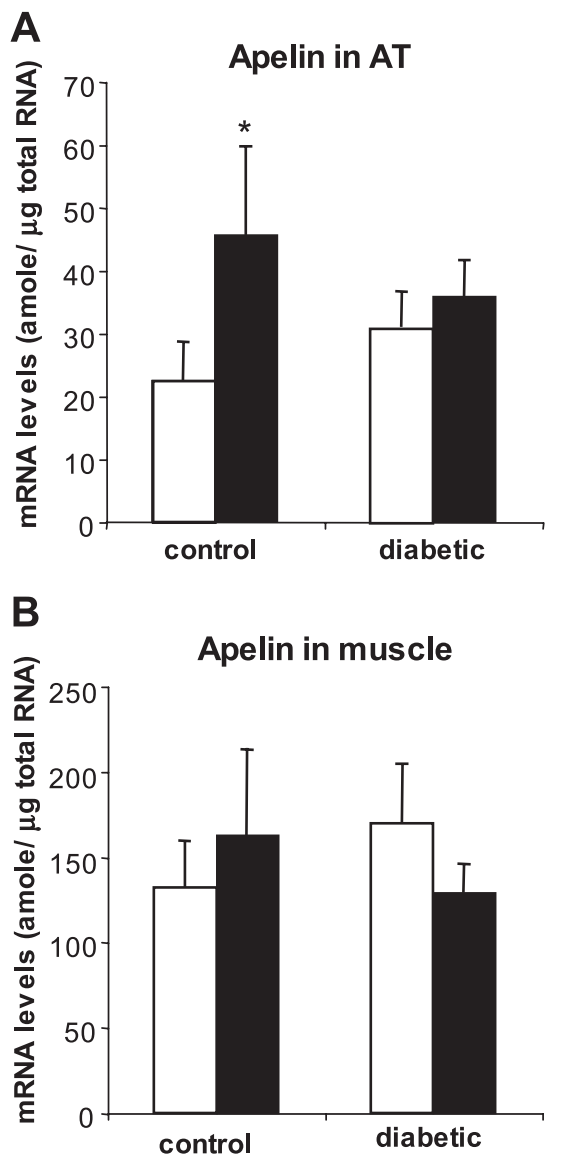
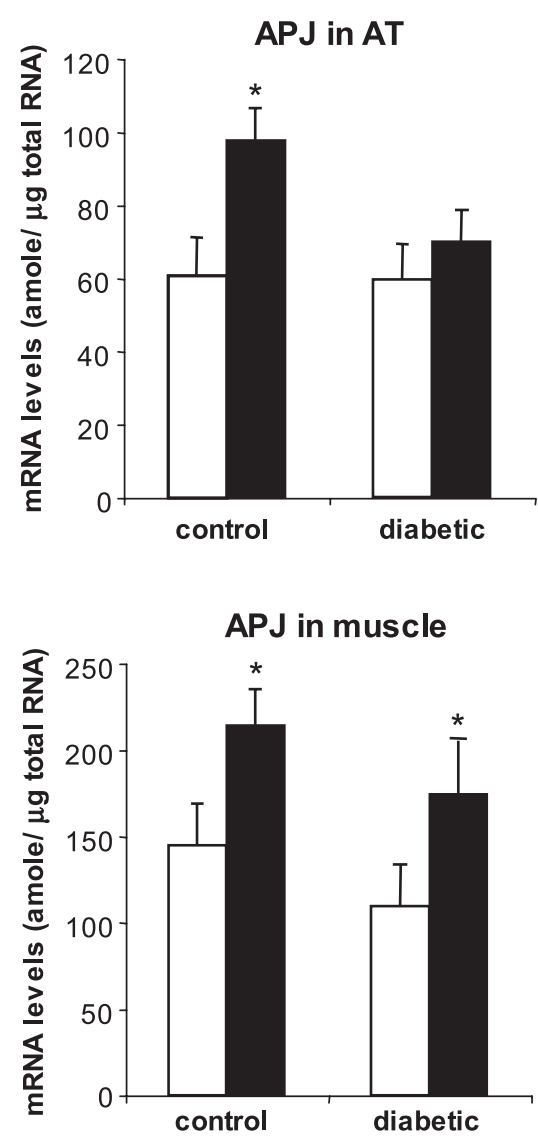
A
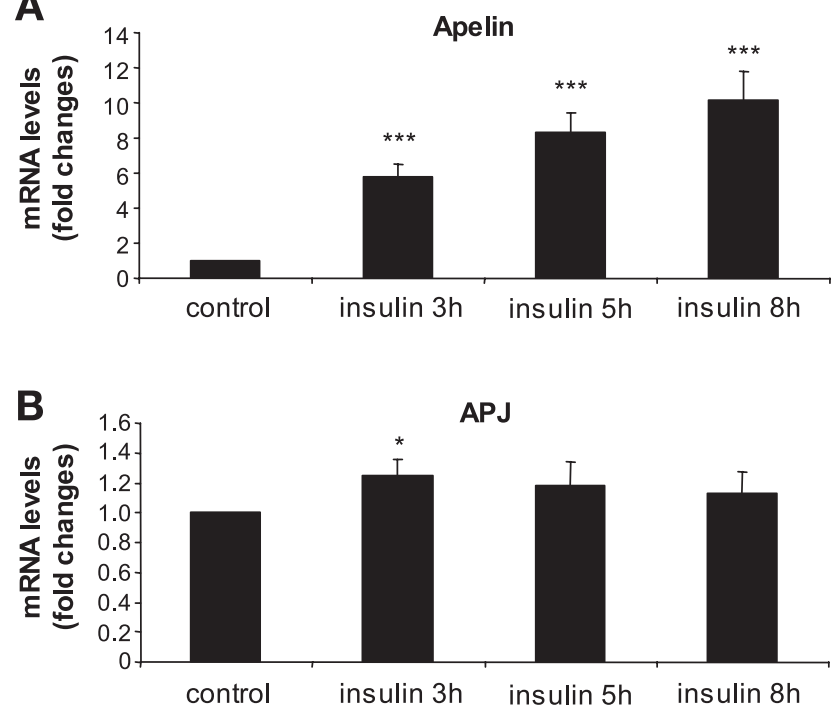

Fig. 6. Expression of apelin $(A)$ and APJ $(B)$ in human cultured adipocytes in response to insulin. Differentiated human adipocytes were stimulated by 100 $\mathrm{nM}$ insulin at the indicated time. Total RNA was extracted and subjected to RT-PCR as indicated in MATERIALS AND METHODS. The mean value for untreated cells (control) was set at 1 . Results are means \pm SE of 3 independent experiments. $* P<0.05$ and $* * * P<0.001$ vs. control.

To confirm the direct involvement of insulin in the observed regulation of apelin and APJ expression in human AT, primary cultures of human adipocytes were treated with insulin in vitro. As shown in Fig. 6, insulin promoted a significant direct effect on apelin expression as soon as $3 \mathrm{~h}$ of stimulation. This effect was more pronounced after $8 \mathrm{~h}$ of treatment. APJ expression was also increased by insulin after $3 \mathrm{~h}$ of treatment.

\section{Plasma Apelin Concentrations in Diabetic Subjects}

There was a clear trend $(P=0.051)$ toward higher plasma apelin concentrations in diabetic subjects $(127.8 \pm 11.6 \mathrm{pg} / \mathrm{ml}$, $n=12)$ compared with controls $(101.7 \pm 3.6 \mathrm{pg} / \mathrm{ml}, n=11)$ despite the interindividual variability in diabetic subjects (Fig. 7A). Moreover, a significant positive correlation was observed between 1) plasma apelin and insulin concentrations (Fig. 7B), 2) plasma apelin and glycemia $(r=0.696, P=0.0002, n=23)$, and 3) plasma apelin and the percentage of glycated hemoglobin $\left(\mathrm{HbA}_{1 \mathrm{c}}\right)($ Fig. $7 C)$, strengthening the relation between apelin and type 2 diabetes.

\section{DISCUSSION}

Insulin resistance in the major insulin-target tissues is widely recognized as a fundamental defect that precedes the development of type 2 diabetes. AT-secreted factors called adipokines have been shown to play an important role in the link between obesity and insulin resistance. Adipokines have either insulinsensitizing effects or contribute to the induction of insulin resistance (5). Therefore, in the present study, the regulation of apelin, newly identified as an adipokine stimulating glucose uptake (8), and of its receptor APJ have been investigated in AT and skeletal muscle during insulin-resistant and diabetic states. We showed that apelin and APJ mRNA expression exhibit tissue-specific regulation and are differentially regulated between insulin-resistant and diabetic states.
The apelin expression profile was different in AT and skeletal muscle during the onset of type 2 diabetes in mice. Indeed, we observed that, in HFD-fed mice, apelin expression was increased in AT but not in muscle compared with chowfed control mice. A tendency to such elevated apelin levels was also observed in young $d b / d b$ compared with old $d b / d b$ mice, exhibiting a more pronounced insulin-resistant state. In old $d b / d b$ mice, apelin expression in AT was similar to control mice. In skeletal muscle, apelin expression was similar in young and old $d b / d b$ mice and decreased compared with control mice. This means that, in a less deleterious state of insulin resistance (observed mainly in HF-fed mice), apelin expression can be upregulated specifically in AT. These data
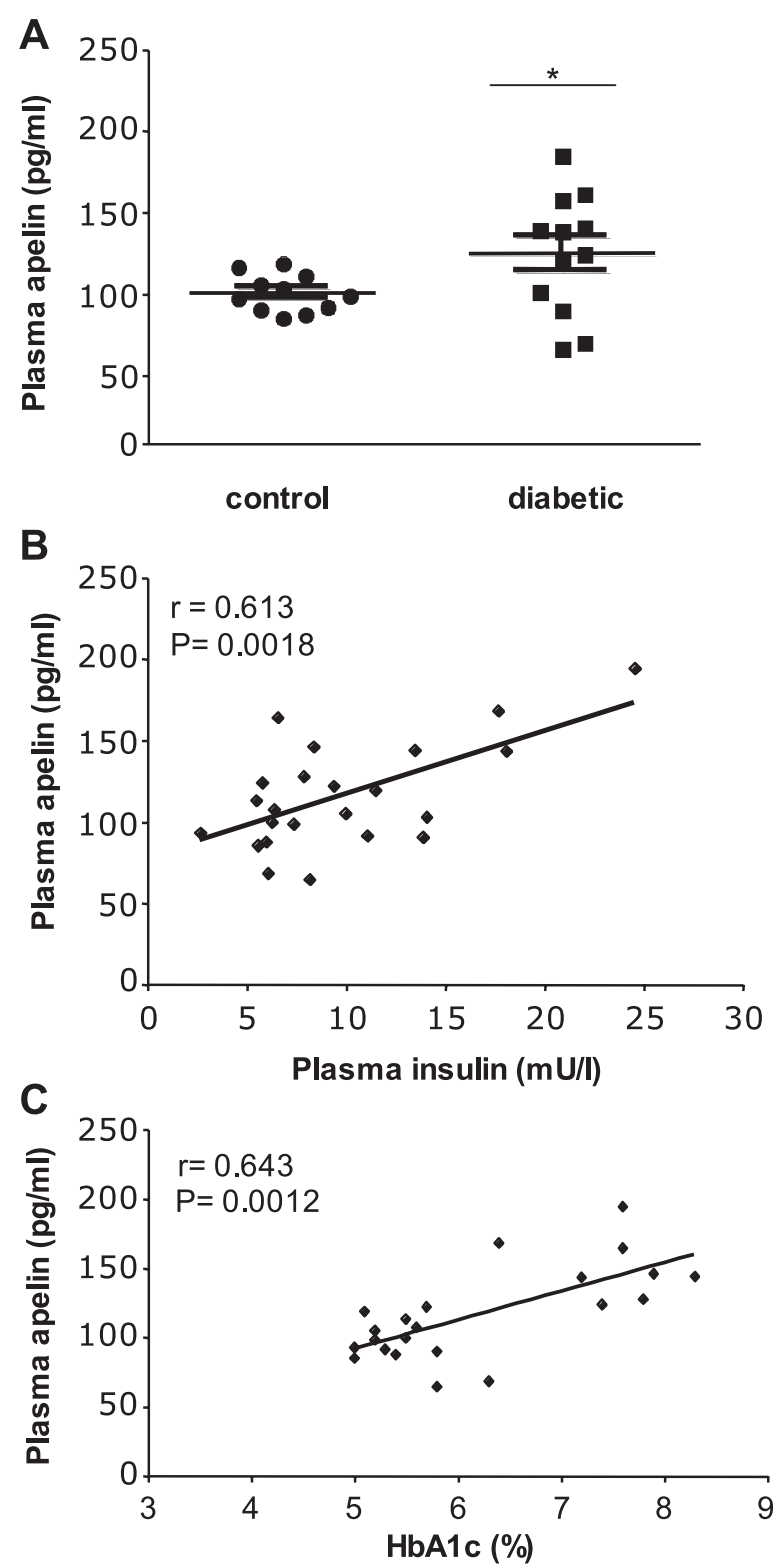

Fig. 7. Human plasma apelin concentrations in control and diabetic patients. $A$ : individual values and means $\pm \mathrm{SE}$ of control $(n=11)$ and diabetic $(n=12)$ subjects. $* P<0.05$ vs. control. $B$ : correlation between plasma apelin and insulin concentrations in all subjects $(n=23)$. $C$ : correlation between plasma apelin and $\% \mathrm{HbA}_{1 \mathrm{c}}$ in all subjects $(n=23)$. Spearman's correlation coefficients $(r)$ and $P$ values are indicated. 
suggest that insulin sensitivity of AT is preserved or higher when compared with skeletal muscle in the model of HFinduced insulin resistance. This is supported by a recent study showing that, after $14 \mathrm{wk}$ of HFD in mice, AT was more sensitive in response to insulin regarding protein kinase B phosphorylation compared with liver or muscle (15).

During fasting/refeeding transition, an increase of apelin mRNA was observed in both AT and muscle of HF-fed mice but not in those of $d b / d b$ mice. Among the different parameters modified during the fasted/refed states, one candidate involved in the regulation of apelin could be insulin, as previously reported (2). Sartipy and Loskutoff (20) showed that, in metabolically insulin-resistant adipocytes (3T3-L1), different genes continue to respond to insulin, suggesting that some signaling pathways involved in gene transcription remain insulin sensitive (19). This hypothesis could be applied to the regulation of apelin expression in HF-fed mice but not in $d b / d b$ mice. Thus it seems that, in severe insulin resistance ( $d b / d b$ mice), hyperinsulinemia fails to induce transcription of the apelin gene or induce a downregulation of apelin.

APJ expression was also differently regulated depending on the tissue studied and the pathological state of the mice. In AT, APJ follows the same expression profile as apelin, whereas, in muscle, APJ mRNA levels decrease with the severity of insulin resistance. Surprisingly, in AT of young $d b / d b$, APJ expression was similar to that in old $d b / d b$ mice. It seems that maximal downregulation of APJ was already obtained in AT of young $d b / d b$ mice compared with HF-fed mice, suggesting that young $d b / d b$ mice were probably more insulin resistant than HF-fed mice. Downregulation of APJ mRNA and protein levels has been described in aorta from diabetic $d b / d b$ mice (24). This study also showed that apelin treatment, despite a depressed expression of APJ, reversed the altered aortic vascular responsiveness to angiotensin or acetylcholine observed in $d b / d b$ mice (24). We recently showed that, in HF-fed obese and insulin-resistant mice, exogenous apelin during a hyperinsulinemic-euglycemic clamp increases glucose utilization in muscle (8). Thus, in HF-fed mice, the amount of APJ mRNA levels and, consequently, the number of receptor are probably sufficient to mediate apelin's metabolic effects. However, in $d b / d b$ mice, it is not known whether the marked decrease of APJ expression in muscle could have pathological implications.

In humans, the literature reported apelin and APJ regulation in the cardiac muscle in different cardiovascular diseases (6) or in AT during obesity or weight loss $(4,12)$. We report here, for the first time, parallel measurements of apelin and APJ expression in skeletal muscle and AT of diabetic subjects. There was a trend for a decreased APJ expression in muscle but not in AT of healthy control subjects and of type 2 diabetic patients. Interestingly, at the end of the hyperinsulinemic clamp, an increase of APJ expression in muscle of diabetic subjects is observed, indicating a short-term regulation by insulin specifically in this tissue. Apelin expression in AT and muscle was not significantly modified by insulin in diabetic subjects.

Although apelin expression was not increased in AT and muscle of highly insulin-resistant $d b / d b$ mice or in diabetic patients, plasma apelin levels were higher than in control mice or subjects. In HFD mice, plasma apelin was also increased in parallel with increased apelin expression in AT. Taken together, these results suggest that apelin mRNA levels in AT cannot predict plasma apelin levels. Indeed, plasma apelin levels did not correlate with body fat mass in $d b / d b$ mice (data not shown). In the present study, we showed that, in humans, plasma apelin correlates positively with plasma insulin concentrations but also with the percentage of $\mathrm{HbA}_{1 \mathrm{c}}$. These different studies reveal that apelin might be more associated to type 2 diabetes than obesity itself and that increased apelin levels could constitute a compensatory mechanism to reduce insulin resistance. Moreover, rosiglitazone or metformin monotherapy in diabetic patients was shown to increase plasma apelin levels together with improved glycemic control (14). In the diabetic state or in severe insulin resistance, the levels of endogenous apelin might be insufficient or inefficient to counteract insulin resistance. Another hypothesis could be the settlement of an apelin resistance. The source and the mechanisms leading to increased circulating apelin remain to be clarified.

In conclusion, the present study highlights the influence of insulin resistance and type 2 diabetes on the regulation of apelin and APJ in AT and skeletal muscle both in mice and humans. In a mouse model displaying severe insulin resistance, the most striking result is a decrease of APJ expression in skeletal muscle. Moreover, APJ expression is not regulated during fasting/refeeding conditions in skeletal muscle of insulin-resistant mice. In diabetic subjects, there is no clear modification of apelin or APJ expression in either tissue. Interestingly, short-term regulation by insulin during the clamp increased APJ expression only in skeletal muscle. It will be important in future studies to establish whether modulation of APJ expression in skeletal muscle has therapeutic benefits in terms of glucose disposal in patients with type 2 diabetes. Our data also demonstrate that differences exist between humans and mice regarding the regulation of the apelin/APJ system in insulin-sensitive tissues, underlining a need for specific clinical and longitudinal studies in humans to better define the pathophysiological role of this system in metabolic diseases such as type 2 diabetes.

\section{ACKNOWLEDGMENTS}

We gratefully acknowledge the animal facilities staff (service de Zootechnie), Dr F. Praddaude (INSERM U858, I2MR Toulouse), and the phenotypage plateforme Anexplo of Toulouse from IFR150. We also acknowledge the nurse and technician staff of the Centre de Recherche en Nutriton Humaine de Lyon for excellent work with the patients.

\section{DISCLOSURES}

No conflicts of interest are declared by the authors.

\section{REFERENCES}

1. Atluri P, Morine KJ, Liao GP, Panlilio CM, Berry MF, Hsu VM, Hiesinger W, Cohen JE, Woo JY. Ischemic heart failure enhances endogenous myocardial apelin and APJ receptor expression. Cell Mol Biol Lett 12: 127-138, 2007.

2. Boucher J, Masri B, Daviaud D, Gesta S, Guigne C, Mazzucotelli A, Castan-Laurell I, Tack I, Knibiehler B, Carpene C, Audigier Y, Saulnier-Blache JS, Valet P. Apelin, a newly identified adipokine upregulated by insulin and obesity. Endocrinology 146: 1764-1771, 2005.

3. Carpéné C, Dray C, Attané C, Valet P, Portillo MP, Churruca I, Milagro FI, Castan-Laurell I. Expanding role for the apelin/APJ system in physiopathology. J Physiol Biochem 63: 359-373, 2007.

4. Castan-Laurell I, Vítkova M, Daviaud D, Dray C, Kováciková M, Kovacova Z, Hejnova J, Stich V, Valet P. Effect of hypocaloric diet-induced weight loss in obese women on plasma apelin and adipose tissue expression of apelin and APJ. Eur J Endocrinol 158: 905-910, 2008. 
5. Catalán V, Gómez-Ambrosi J, Rodríguez A, Salvador J, Frühbeck G. Adipokines in the treatment of diabetes mellitus and obesity. Expert Opin Pharmacother 10: 239-254, 2009.

6. Chandrasekaran B, Dar O, McDonagh T. The role of apelin in cardiovascular function and heart failure. Eur J Heart Fail 10: 725-732, 2008.

7. Debard C, Laville M, Berbe V, Loizon E, Guillet C, Morio-Liondore B, Boirie Y, Vidal H. Expression of key genes of fatty acid oxidation, including adiponectin receptors, in skeletal muscle of Type 2 diabetic patients. Diabetologia 47: 917-925, 2004.

8. Dray C, Knauf C, Daviaud D, Waget A, Boucher J, Buléon M, Cani PD, Attané C, Guigné C, Carpéné C, Burcelin R, Castan-Laurell I, Valet $\mathbf{P}$. Apelin stimulates glucose utilization in normal and obese insulinresistant mice. Cell Metab 8: 437-445, 2008.

9. Ducluzeau PH, Perretti N, Laville M, Andreelli F, Vega N, Riou JP, Vidal H. Regulation by insulin of gene expression in human skeletal muscle and adipose tissue. Evidence for specific defects in type 2 diabetes. Diabetes 50: 1134-1142, 2001.

10. Erdem G, Dogru T, Tasci I, Sonmez A, Tapan S. Low plasma apelin levels in newly diagnosed type 2 diabetes mellitus. Exp Clin Endocrinol Diabetes 116: 289-292, 2008.

11. Heinonen MV, Purhonen AK, Miettinen P, Paakkonen M, Pirinen E, Alhava E, Akerman K, Herzig KH. Apelin, orexin-A and leptin plasma levels in morbid obesity and effect of gastric banding. Regul Pept 130: 7-13, 2005.

12. Heinonen MV, Laaksonen DE, Karhu T, Karhunen L, Laitinen T, Kainulainen S, Rissanen A, Niskanen L, Herzig KH. Effect of dietinduced weight loss on plasma apelin and cytokine levels in individuals with the metabolic syndrome. Nutr Metab Cardiovasc Dis 19: 626-633, 2009.

13. Iwanaga Y, Kihara Y, Takenaka H, Kita T. Down-regulation of cardiac apelin system in hypertrophied and failing hearts: possible role of angiotensin II-angiotensin type 1 receptor system. J Mol Cell Cardiol 41: 798-806, 2006.

14. Kadoglou NP, Tsanikidis H, Kapelouzou A, Vrabas I, Vitta I, Karayannacos PE, Liapis CD, Sailer N. Effects of rosiglitazone and metformin treatment on apelin, visfatin, and ghrelin levels in patients with type 2 diabetes mellitus. Metabolism 59: 373-379, 2009.
15. Kim F, Pham M, Maloney E, Rizzo NO, Morton GJ, Wisse BE, Kirk EA, Chait A, Schwartz MW. Vascular inflammation, insulin resistance, and reduced nitric oxide production precede the onset of peripheral insulin resistance. Arterioscler Thromb Vasc Biol 28: 1982-1988, 2008.

16. Laville M, Auboeuf D, Khalfallah Y, Vega N, Riou JP, Vidal H. Acute regulation by insulin of phosphatidylinositol-3-kinase, Rad, Glut 4, and lipoprotein lipase mRNA levels in human muscle. J Clin Invest 98: 43-49, 1996.

17. Li L, Yang G, Li Q, Tang Y, Yang M, Yang H, Li K. Changes and relations of circulating visfatin, apelin, and resistin levels in normal, impaired glucose tolerance, and type 2 diabetic subjects. Exp Clin Endocrinol Diabetes 114: 544-548, 2006.

18. Ren F, Zhang N, Sun J, Yang J. Low plasma apelin in newly diagnosed type 2 diabetes in Chinese people. Diabetes Care 32: e150, 2009.

19. Samad F, Pandey M, Bell PA, Loskutoff DJ. Insulin continues to induce plasminogen activator inhibitor 1 gene expression in insulin-resistant mice and adipocytes. Mol Med 6: 680-692, 2000.

20. Sartipy P, Loskutoff DJ. Expression profiling identifies genes that continue to respond to insulin in adipocytes made insulin-resistant by treatment with tumor necrosis factor-alpha. J Biol Chem 278: $52298-$ 52306, 2003.

21. Soriguer F, Garrido-Sanchez L, Garcia-Serrano S, Garcia-Almeida JM, Garcia-Arnes J, Tinahones FJ, Garcia-Fuentes E. Apelin levels are increased in morbidly obese subjects with Type 2 Diabetes Mellitus. Obes Surg 19: 1574-1580, 2009.

22. Tatemoto K, Hosoya M, Habata Fujii RY, Kakegawa T, Zou MX, Kawamata Y, Fukusumi S, Hinuma S, Kitada C, Kurokawa T, Onda H, Fujino M. Isolation and characterization of a novel endogenous peptide ligand for the human APJ receptor. Biochem Biophys Res Commun 251: 471-476, 1998.

23. Yue P, Jin H, Aillaud-Manzanera M, Deng AC, Azuma J, Asagami T, Kundu RK, Reaven T, Quertermous GM, Tsao PS. Apelin is necessary for the maintenance of insulin sensitivity. Am J Physiol Endocrinol Metab 298: E59-E67, 2010.

24. Zhong JC, Yu XY, Huang Y, Yung LM, Lau CW, Lin SG. Apelin modulates aortic vascular tone via endothelial nitric oxide synthase phosphorylation pathway in diabetic mice. Cardiovasc Res 74: $388-$ $395,2007$. 